
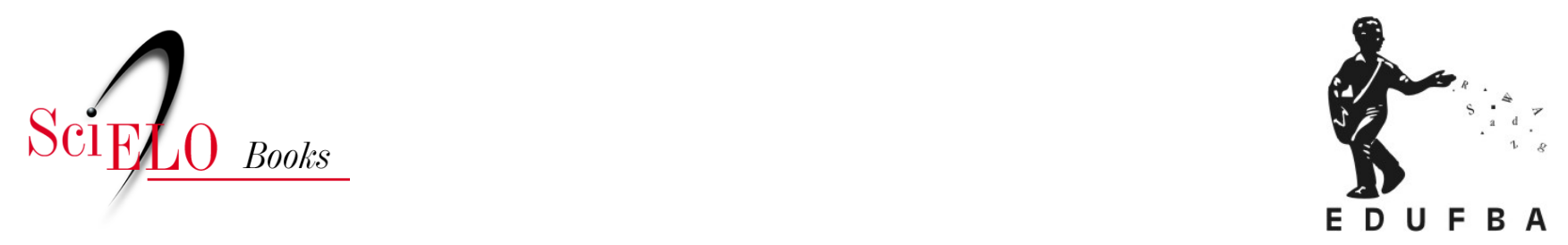

\title{
0 gerenciamento ambiental das perdas de catalisador usado nas unidades de craqueamento catalítico em refinarias de petróleo riscos à saúde pública e ao meio ambiente
}

\author{
Wanderley Ferreira da Silva Júnior \\ Severino Soares Agra Filho \\ Fernando Martins Carvalho
}

\section{SciELO Books / SciELO Livros / SciELO Libros}

SILVA JÚNIOR, W.F., AGRA FILHO, S.S., and CARVALHO, F.M. O gerenciamento ambiental das perdas de catalisador usado nas unidades de craqueamento catalítico em refinarias de petróleo: riscos à saúde pública e ao meio ambiente. In: FERNANDES, R.C.P., LIMA, M.A.G., and ARAÚJO, T.M., comps. Tópicos em saúde, ambiente e trabalho: um olhar ampliado [online]. Salvador: EDUFBA, 2014, pp. 359-379. ISBN: 978-65-5630-012-2. https://doi.org/10.7476/9786556300122.0018. \section{International license.}

All the contents of this work, except where otherwise noted, is licensed under a Creative Commons Attribution 4.0

Todo o conteúdo deste trabalho, exceto quando houver ressalva, é publicado sob a licença Creative Commons Atribição 4.0. 


\section{O gerenciamento ambiental das perdas de catalisador usado nas unidades de craqueamento catalítico em refinarias de petróleo: riscos à saúde pública e ao meio ambiente}

Wanderley Ferreira da Silva Júnior

Severino Soares Agra Filho

Fernando Martins Carvalho

\section{Introdução}

A indústria de petróleo e seus derivados têm papel destacado na economia mundial, pois são responsáveis pela produção de fonte energética e insumos para a indústria petroquímica. As unidades de craqueamento das refinarias de petróleo são responsáveis pelo processo de conversão de resíduos das unidades de destilação em produtos com alto valor agregado. (CB\&I, 2009; WIKIMEDIA, 2011) A utilização do catalisador aumenta a produção de gasolina em $27 \%$ e reduz a produção total de óleo combustível de $59 \%$ para $37 \%$, o que representa razoável vantagem econômica e ambiental. (BIRA, 2004; CORRADI, 2008; FCC, 2010) Por outro lado, essas unidades são importantes fontes geradoras de poluentes atmosféricos. (BAPTISTA, 2005)

De acordo com a Environmental Protection Agency (1996), o material particulado descartado pelas chaminés das unidades de craqueamento, em leito fluidizado (catalisador gasto ou de equilíbrio), apesar de passar por um processo de regeneração do coque, este processo não elimina os metais pesados. O descarte de catalisador usado (E-CAT) das unidades de craqueamento é uma preocupação mundial para a saúde ambiental, por conter sílica e estar sujeito à contaminação por 
coque e metais pesados, a exemplo de Níquel, Vanádio e Antimônio. (BAHIA, 1987; MARIANO, 2001; AFONSO; AGUIAR; SILVA, 2003; BAPTISTA, 2005)

De acordo com informações da Fábrica Carioca de Catalisadores - FCC S.A -, os finos de catalisador correspondem às partículas com diâmetro aerodinâmico entre 0 e $40 \mu \mathrm{m}$ e são economicamente desejáveis às unidades de craqueamento catalítico. (RIBEIRO; FLORES, 2008) A fração inalável $\left(\mathrm{PM}_{10}\right)$ pode atingir a mucosa nasal, faringe, laringe e parte superior da traqueia, correspondendo às vias aéreas superiores. Partículas com diâmetro aerodinâmico $\leq 2,5 \mu \mathrm{m}\left(\mathrm{PM}_{2,5}\right)$ atingem a parte inferior da traqueia, brônquios, bronquíolos e alvéolos. A fração respirável, partículas com diâmetro aerodinâmico $\leq 1 \mu \mathrm{m}\left(\mathrm{PM}_{1,0}\right)$, são absorvidas pelo sangue, distribuídas pelo organismo e ao final metabolizadas por meio de biotransformações mediadas por enzimas. (SALGADO, 2003)

Segundo norma do Ministério do Trabalho e Emprego do Brasil, anexo 11 da NR-15, alguns agentes químicos cujos limites de tolerância possam ser ultrapassados em algum momento da jornada de trabalho se enquadram em valores teto, que, de acordo com a NR-03, coloca o trabalhador sob grave e iminente risco, pois a condição ambiental do trabalho pode causar doença profissional com lesão grave à integridade física do trabalhador. Neste caso, a unidade operacional é passível de interdição ou embargo. O cálculo do limite de tolerância para poeira total (respirável e não-respirável) deve utilizar o percentual de sílica livre identificado no material particulado. (BRASIL, 1978)

A segunda maior Refinaria do Brasil em capacidade instalada, caso de estudo desta pesquisa, possui capacidade de 323 mil barris por dia e emprega 1.409 trabalhadores diretos. (PETROBRAS, s.d; FIEB, 2010) A refinaria localiza-se no município de São Francisco do Conde, com população estimada de 30.069 habitantes e Produto Interno Bruto per capita de USD 125.483,88, um dos mais elevados do Brasil. (IBGE, 2007)

O catalisador, quando ainda não utilizado, é composto de $58 \%$ a $60 \%$ de óxido de silício amorfo, de $36 \%$ a $37 \%$ de óxido de alumínio e concentrações de vanádio, níquel e antimônio que variam de 0,0\% a 0,03\%. (CERQUEIRA; RAWET; PINTO, 2000; PETROBRAS, 2002 apud SILVA-JUNIOR et al, 2010, p.45; FCC, 2010) Diante da possibilidade de 
emissões de material particulado conterem essas substâncias, entidades nacionais e internacionais estabelecem limites para as concentrações atmosféricas destas substâncias, em $\mathrm{mg} / \mathrm{m}^{3}$, em ambientes ocupacionais. Informações sobre concentrações atmosféricas de óxido de silício amorfo e de óxido de alumínio não foram disponibilizadas pela refinaria. Entretanto, os valores esperados por Cerqueira (2001) e compostos do catalisador descritos pelo fabricante FCC S.A. e da ACGIH (2010), revelam que as concentrações de metais pesados identificadas na poeira de catalisador exausto desta refinaria, estão muito acima dos padrões nacionais e internacionais.

Com o desenvolvimento da indústria de petróleo, as 15 unidades de craqueamento catalítico em leito fluidizado da Petrobras no Brasil passaram a descartar 40.000 toneladas/ano de catalisador gasto ou de equilíbrio. Três dessas unidades integram o PACRC (Petrobras Advanced Conversor Residue Cracking), reutilizando 15.000 toneladas/ ano de catalisador usado. Estas três unidades foram desenvolvidas e patenteadas pelo Centro de Pesquisa da Petrobras (CENPES) e representam cerca de U\$ 330 milhões em rentabilidade para a empresa. (CORRADI, 2008) No entanto, à medida que aumenta o ciclo de reutilização do catalisador, também se eleva a contaminação do seu resíduo por hidrocarbonetos policíclicos aromáticos, compostos reconhecidamente cancerígenos. (CERQUEIRA; RAWET; PINTO, 2000; CERQUEIRA et al., 2001; CERQUEIRA; BAPTISTA; FUSCO, 2006) O catalisador virgem ou silício aluminato de terras raras é o catalisador que ainda não foi utilizado pelas unidades de craqueamento. Segundo a ficha de informação de segurança disponibilizada pela Fábrica Carioca de Catalisadores, esse composto químico não possui limite de exposição ocupacional estabelecido, além de ser considerado como relativamente seguro para o meio ambiente e seres humanos, apesar de poder causar irritações na pele, olhos e aparelho respiratório. (FCC, 2010) Cabe ressaltar que consultores técnicos da Petrobras em craqueamento catalítico advertem que as refinarias de petróleo têm processado cargas cada vez mais pesadas e com maior severidade (sic). Isto tem implicado em maiores contaminações do catalisador virgem, devido aos maiores teores de contaminantes na carga e maior formação de coque no processo de craqueamento catalítico. (COSTA et al., 2004) 
Uma pesquisa realizada em uma refinaria localizada na cidade de Paulínia, Brasil, identificou uma taxa de emissão de catalisador pelas chaminés em torno de 5 toneladas/dia. Cerca de $50 \%$ desse resíduo era depositado em sua própria área interna e foram encontradas partículas de catalisador em até 7,46 milhas de distância da fonte de emissão do poluente. (ALMEIDA, 2000) Esta perda está relacionada com a eficiência dos ciclones que só retém partículas com diâmetro aerodinâmico $\geq 5 \mu \mathrm{m}$, isto é, antes dos ciclones sofrerem desgastes em seus componentes internos pela elevada abrasividade do catalisador. (SBRT, 2007; CORRADI, 2008)

Este trabalho tem como objetivo avaliar o gerenciamento ambiental das perdas de catalisador da segunda maior refinaria do Brasil, buscando identificar e caracterizar os destinos desse resíduo. Mais especificamente, o trabalho buscou: a) identificar e caracterizar as fontes de geração de emissão e destinação dos resíduos e as perdas de catalisador de craqueamento; b) caracterizar os procedimentos de gestão ambiental adotados pela Refinaria para as perdas de catalisador de craqueamento; e c) avaliar a pertinência e adequação das medidas adotadas quanto aos aspectos normativos e institucionais.

\section{Metodologia}

A metodologia adotada foi a de estudo de caso, usando abordagem quali-qualitativa. A empresa estudada é a segunda maior refinaria do Brasil em capacidade instalada, com duas unidades de craqueamento, a saber: uma Unidade de Craqueamento Catalítico em Leito Fluidizado (UFCC), com capacidade de processamento de até $5.000 \mathrm{~m} 3 /$ dia, e uma Unidade de Craqueamento Catalítico de Resíduo em Leito Fluidizado (URFCC), com capacidade de processamento de até $10.000 \mathrm{~m} 3 /$ dia. (BIRA, 2004)

A refinaria foi certificada em Responsabilidade Social pela Norma SA-8000, fato que implicaria em compromisso de transparência junto às partes interessadas em relação aos seus processos produtivos e possíveis impactos à saúde e meio ambiente das populações sob sua influência. (SAI, [2008])

Os procedimentos metodológicos da pesquisa envolveram revisão da legislação pertinente e dos documentos existentes nos diversos 
órgãos relacionados à questão, incluindo as informações constantes do Inquérito civil público 003.1.13889/2007, formado pelo Ministério Público Estadual - Primeira Promotoria de Justiça do Meio Ambiente de Salvador, para averiguar denúncia de degradação ambiental consistente no lançamento de metais pesados causando contaminação de moluscos e adoecimento de trabalhadores pela RLAM/PETROBRAS. A coleta de dados fundamentou-se em documentos institucionais do período de 1998 a 2010, entre eles, os indicadores sociais e ambientais, internos e externos, publicados no balanço social da empresa. (IBASE, 2010)

A partir dos dados obtidos, buscou-se caracterizar, identificar destinos e estimar as perdas de catalisador de craqueamento da Refinaria e as possíveis populações atingidas: trabalhadores e comunidades.

A Gerência de Saúde, Meio Ambiente e Segurança e a Gerência de Meio Ambiente da Refinaria, foram consultadas sobre o Plano de Gerenciamento de Resíduos Sólidos (PGRS) adotado pela Refinaria, bem como sobre a quantidade de catalisador de craqueamento que é descartado pela mesma e se existiam estudos epidemiológicos em populações sob influência da Refinaria, em especial, sobre a comunidade vizinha de Caípe. (PETROBRAS/ABAST/PG-1T-00020-A, 2006; SAI, [2008])

Considerando que a legislação ambiental no Brasil (2003), determina que as informações existentes no Sistema Nacional do Meio Ambiente (SISNAMA) sejam de domínio público e que os órgãos de controle ambiental sejam responsáveis pela fiscalização e aprovação de atividades e sistemas de produção que possam provocar degradação ambiental, foram solicitadas informações às partes envolvidas sobre as possíveis licenças e autorizações relativas ao manuseio, transporte, armazenamento, incineração e coprocessamento do resíduo de catalisador de craqueamento da Refinaria. (BRASIL, 1989; SALGADO, 2003)

Diante das dificuldades em obter informações da fonte geradora do resíduo dos órgãos de controle ambiental e da empresa receptora de parte do resíduo, foram utilizadas as informações disponíveis no inquérito civil público (003.1.13889/2007), formado pela Primeira Promotoria de Justiça do Meio Ambiente, da Comarca de Salvador, para investigar o possível lançamento de metais pesados e adoecimento de trabalhadores causados pela Refinaria em estudo. Foram realizadas visitas às Promotorias do Meio Ambiente, da Comarca de Salvador e de São Francisco do Conde, com o objetivo de ter acesso aos originais e 
estudar detalhadamente os seus documentos ali contidos, baseado na Lei Federal no 9.099. (BRASIL, 1995)

A pesquisa não envolveu contato direto, nem lidou com dados individuais das populações em estudo, sendo assim, não foi necessário submetê-la ao Comitê de Ética de Pesquisa, mas atendeu as conformidades descritas no Código Internacional de Ética Médica. (BRASIL, 1996; WMA, s.d.) Neste sentido, manteve-se o compromisso ético de que os resultados fossem apresentados à comunidade e enviados às autoridades locais responsáveis pela saúde e meio ambiente da região, para que pudessem incluir as ações adequadas.

\section{Resultados e discussão}

A partir dos procedimentos metodológicos desenvolvidos, foram identificados quatro pontos de perda/descarte de catalisador das unidades de craqueamento da refinaria, conforme indicado na Figura 1, a saber: o descarte de rotina operacional em torno de 5 toneladas de catalisador exausto, após esgotado os ciclos de regeneração e a perda direta para a atmosfera nos seguintes pontos: emissões de finos após ciclones dos regeneradores; perdas fugitivas por vazamentos por equipamentos e conexões, que são coletadas nas varrições das áreas internas da unidade; e as perdas pelas chaminés dos fornos e caldeiras de finos de catalisador contidos no óleo decantado usado como combustível na unidade. Em condições normais de operação, a perda direta de catalisador para o meio ambiente supera 6 toneladas/dia. Esta perda direta de catalisador ocorre em apenas uma das unidades de craqueamento, pela mistura gasosa de poluentes gerados no processo de catalítico com os finos de catalisador, que passaram pelos ciclones e foram arrastados através das chaminés dos regeneradores. Porém, em situações atípicas, estas perdas chegam a 41,72 toneladas/dia. (PETROBRAS/RLAM/OT/ COT, 2007 apud SILVA JÚNIOR, 2010 p. 86 e 87; BRASIL, 2006) 
Figura 1 - Fluxograma de uma unidade de craqueamento com riser. Adaptada da fonte. (KARAN, 2004)

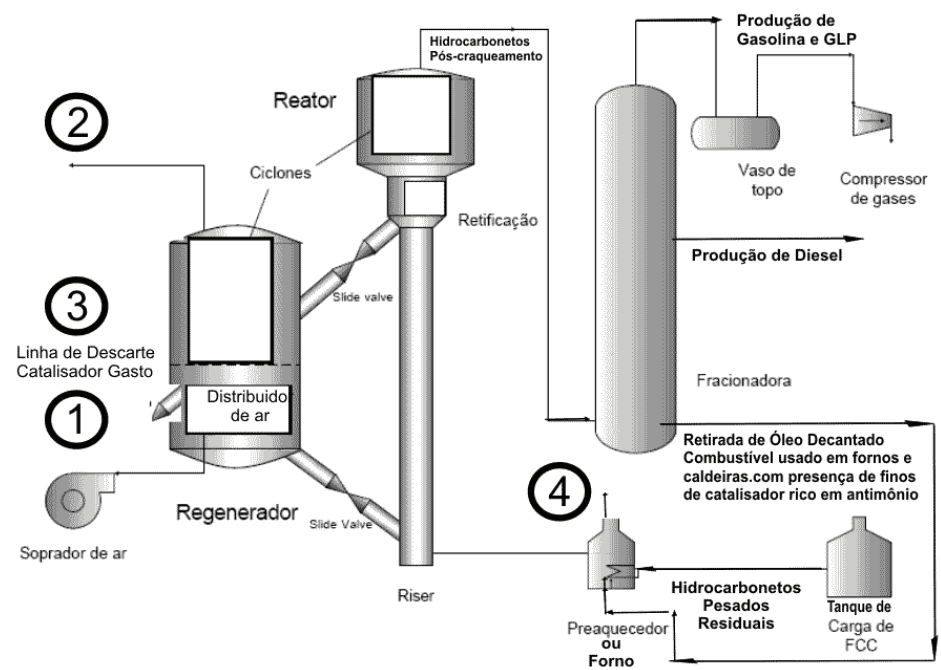

Fonte: (SILVA JUNIOR; AGRA FILHO; CARVALHO, 2010)

As perdas por emissões fugitivas para o meio ambiente, ocorrem por vazamentos do produto nos equipamentos, tubulações e conexões sob pressão, sendo incorporadas ao Resíduo Sólido de Varrição (RSV) da refinaria. Segundo o representante dos trabalhadores na Comissão Interna de Prevenção de Acidentes de Trabalho (CIPA), este resíduo seria removido da área industrial e agregado a outros resíduos por trabalhadores terceirizados. Esta atividade estaria sendo realizada sem o uso correto de equipamento de proteção individual. Uma síntese da origem, quantidade e respectivas destinações finais, bem como as medidas praticadas, estão indicadas no Quadro 1. 
Quadro 1 - Identificação das fontes, destino, quantidades e medidas adotadas para os resíduos/emissões de catalisador de craqueamento.

\begin{tabular}{|l|l|l|l|}
\hline $\begin{array}{c}\text { FONTE DE GERAÇÃO } \\
\text { DO RESÍDUO DE } \\
\text { CATALISADOR }\end{array}$ & \multicolumn{1}{|c|}{ DESTINO } & QUANTIDADE & MEDIDAS \\
\hline $\begin{array}{l}\text { Ponto 1 } \\
\begin{array}{l}\text { Descarte rotineiro de } \\
\text { catalisador exausto }\end{array}\end{array}$ & $\begin{array}{l}\text { Cimenteiras locali- } \\
\text { zadas no Estado de } \\
\text { Sergipe }\end{array}$ & $\begin{array}{l}\text { Cerca de 5 tone- } \\
\text { ladas/ dia }\end{array}$ & $\begin{array}{l}\text { Reutilização na } \\
\text { produção de } \\
\text { cimento (Meio } \\
\text { Ambiente) }\end{array}$ \\
\hline Ponto 2 & $\begin{array}{l}\text { Cerca de 50\% na área } \\
\text { interna da RLAM }\end{array}$ & & \\
\cline { 2 - 2 } $\begin{array}{l}\text { Perda de finos de catalisa- } \\
\text { dor pelos ciclones }\end{array}$ & $\begin{array}{l}\text { Comunidades em } \\
\text { torno da RLAM }\end{array}$ & \multirow{2}{*}{$\begin{array}{l}\text { Superior a 6 to- } \\
\text { neladas por dia }\end{array}$} & $\begin{array}{l}\text { Disposição no } \\
\text { meio ambiente } \\
\text { sem tratamento } \\
\text { adequado }\end{array}$ \\
\hline Ponto 3 & $\begin{array}{l}\text { Área interna da RLAM } \\
\text { (RSV) }\end{array}$ & \\
\hline $\begin{array}{l}\text { Perda pelas emissões } \\
\text { fugitivas }\end{array}$ & $\begin{array}{l}\text { Cerca de 50\% na área } \\
\text { interna da RLAM }\end{array}$ & \\
\cline { 1 - 2 } Ponto 4 & $\begin{array}{l}\text { Comunidades em } \\
\text { torno da RLAM }\end{array}$ & \\
\hline Perda pelas chaminés & & \\
\hline
\end{tabular}

Fonte: (SILVA JÚNIOR; AGRA FILHO; CARVALHO, 2009.)

\section{Medidas de gerenciamento praticadas}

O resíduo de catalisador exausto é transportado por carretas silos, com capacidade média de 21 toneladas de catalisador, por meio de empresas contratadas. Parte desse resíduo vinha sendo transportado para uma fábrica de cimento localizada no Estado de Sergipe, com o objetivo de ser co-processado na produção de cimento. (PETROBRAS, 2007 apud BAHIA, 2007, p. 186) O descarte de catalisador exausto dos silos, equipamentos que integram às unidades de craqueamento da refinaria é uma atividade realizada por 72 trabalhadores, técnicos de operação da empresa.

As operações de transferência, armazenamento, adição, retirada, abertura e fechamento de recipientes com resíduos tóxicos ou, sob qualquer outro modo nocivo ao homem, devem ser executadas por pessoal dotado do Equipamento de Proteção Individual (EPI) adequado, continuamente capacitado por treinamento adequado dado pelo 
empregador. (ASSOCIAÇÃO BRASILEIRA DE NORMAS TÉCNICAS, 1992; BRASIL, 1978) Esses trabalhadores estavam expostos à poeira de catalisador em até 2,95 vezes acima da jornada de trabalho permitida pela legislação. (GAIA, 2005 apud SILVA JÚNIOR, 2010 p. 94-97)

O descarte de catalisador exausto para fábricas de cimento é uma medida de gestão questionável, pois, serve apenas para diluir o resíduo de catalisador de craqueamento no cimento. Esse procedimento representa um perigo ao meio ambiente e à saúde pública, uma vez que, mantêm as características iniciais dos metais e substâncias tóxicas persistentes que contaminam o catalisador. No Estado de São Paulo, por exemplo, as fábricas de cimento não são autorizadas pelo órgão de controle ambiental para receptar este tipo de resíduo. (SANTOS, 2005)

No Brasil, o transporte de resíduos perigosos também depende de autorização emitida por órgãos de controle ambiental. No caso da refinaria, esta documentação também está prevista em sua Licença de Operação (LO), em legislação específica em norma da Associação Brasileira de Normas Técnicas. (ASSOCIAÇÃO BRASILEIRA DE NORMAS TÉCNICAS, 1992; BAHIA, 1994; BAHIA, 2001b; BAHIA, 2002; BRASIL, 2003)

A refinaria integra o Programa Petrobras Advanced Conversor Residue Cracking (PAC ${ }^{\mathrm{RC}}$ ) por reutilizar parte do catalisador da UFCC como insumo na URFCC. No entanto, segundo Cerqueira e colaboradores. (2001; 2006), cada reciclo de utilização do catalisador pelas unidades de craqueamento, aumenta a sua contaminação por substâncias tóxicas.

Cabe ressaltar, que a licença de operação da refinaria prevê medições de material particulado em fontes fixas, a exemplo do catalisador exausto dispersado para o meio ambiente, através das chaminés. (BAHIA, 2006) Medições do catalisador exausto não vinham sendo feitas de modo rotineiro.

Diante das medidas identificadas, evidencia-se que o gerenciamento ambiental se restringe a uma destinação para o catalisador usado (exausto). Dessa forma, constatam-se lacunas importantes no gerenciamento dos finos de catalisador, sobretudo, em relação às emissões para atmosfera sem qualquer procedimento de minimização e o devido monitoramento, indicando a existência de sérios riscos para a saúde dos trabalhadores e para as comunidades circunvizinhas, sob possível exposição. Cabe ressaltar ainda que a medida adotada para a utilização 
em cimenteiras torna-se uma transferência de um potencial risco para as comunidades do entorno da fabrica de cimento.

\section{Riscos para saúde dos trabalhadores}

Com base no padrão de responsabilidade social que era adotado pela Refinaria, foram analisados os riscos ambientais aos quais os trabalhadores estavam expostos. Para isto, utilizou-se o Programa de Prevenção a Riscos Ambientais (PPRA), do ano de 2006. O PPRA adota limites de exposição estabelecidos pela NR-15 do Ministério do Trabalho e Emprego ou, quando na inexistência de limites na legislação nacional, utiliza padrões estabelecidos pela NIOSH ou ACGIH. Não foi identificado no PPRA o método de amostragem para a poeira de catalisador, nem seus limites de tolerância. A empresa contratada para a elaboração do PPRA utilizou como referência orientações da Gerência de Saúde, Meio Ambiente e Segurança (SMS) da empresa, em que orienta avaliações apenas para os agentes químicos definidos por ela mesma. (GAIA, 2005 apud SILVA JÚNIOR, 2010 p.94-97) Foram realizadas discussões com estes trabalhadores e os representantes dos trabalhadores, na Comissão Interna de Prevenção de Acidentes de Trabalho (CIPA) e no comitê de Responsabilidade Social pela Norma SA-8000. (BRASIL, 1978; PETROBRAS/ABAST/PG-1T-00020-A, 2006; SAI, 2008)

De acordo com a Portaria $N^{\circ} 3.214$ do Ministério do Trabalho e Emprego, o PPRA consiste em um relatório no qual a empresa deve identificar os grupos homogêneos de exposição (GHE) definidos a partir das atividades dos trabalhadores e seus respectivos postos de trabalho. (BRASIL, 1978) Em cada grupo, os riscos ambientais devem ser identificados, mapeados e registrados em laudo técnico de condições ambientais do trabalho (LTCAT). No caso em estudo, o tempo de jornada de trabalho utilizado para cálculos dos limites de exposição foi de 8 horas. (NIOSH, 2010; ACGIH, 2010)

\section{Riscos para as comunidades circunvizinhas sob possível exposição}

As condições meteorológicas possibilitam estabelecer uma forma de ligação entre a fonte poluidora e o receptor, tendo como referência 
o transporte e a dispersão dos poluentes. (TORRES; MARTINS, 2005) No Nordeste do Brasil e especificamente na Bahia, a direção predominante do vento é de Leste, com flutuações para Sudeste e Nordeste. (SILVA et al., 2002)

O material particulado é um dos poluentes mais importantes da região sob influência da refinaria e provavelmente atinge uma população que vem adoecendo devido à poluição por produtos tóxicos, o que tem chamado à atenção do poder público. (NEVES; MENEZES; ASSUNÇÃO, 2001 NATIVOS, 2010) Com base no estudo de Almeida (2000), estabeleceu-se um raio de ação de 10,8 milhas de distância da fonte e estimou-se uma população de 56.305 habitantes que residem nas cidades de São Francisco do Conde, Madre de Deus e no Distrito de Saubara. (IBGE, 2007)

Dentro deste raio de ação está o distrito de Caípe, localizado a poucos metros de distância da refinaria e na direção dos ventos que provém da empresa, com 11.203 moradores. (IBGE, 2007) A atmosfera de Caípe apresenta níveis significativos de Hidrocarbonetos Policíclicos Aromáticos e de Material Particulado (PM) de provável origem petrogênica. (SILVA JÚNIOR et al., 2009; PPGSAT, 2010)

\section{A precarização do trabalho}

Os dados coletados permitiram identificar a terceirização dos serviços de varrição e limpeza e certa incumbência de responsabilidades às empresas contratadas, responsáveis pelo processo de coleta, armazenamento, transporte e destinação final do catalisador. É importante ressaltar que essas terceirizadas lidam com um resíduo perigoso, Classe I, segundo norma técnica da Associação Brasileira de Normas Técnicas (2004). O elevado grau de precarização influencia no aceite de qualquer labor, submetendo os trabalhadores a riscos operacionais mesmo sob a supervisão da gestão, mais preocupada com a produtividade da organização. (DEJOURS, 1996) Esse quadro proporciona o aparecimento de fragilidades na relação entre os trabalhadores da empresa, decorrentes do processo competitivo que agride a saúde física e mental dos trabalhadores. (GODINHO, 2007; VAZQUEZ, 2009) Quando a organização reduz o seu núcleo estável abaixo de $25 \%$, ela atinge o grau máximo de precarização pelo aumento da 'flexibilização' dos contratos de trabalho. 
(DRUCK et al., 2007) O balanço social da empresa identificou um processo de precarização que atinge cerca de $80 \%$ de sua força de trabalho. (PETROBRAS, 2008 apud IBASE, 2010)

\section{Política ambiental da organização}

A análise do Balanço Social da empresa também indica uma atuação reativa, possivelmente um dos fatores que tem elevado seus custos operacionais. De acordo com os relatórios de exercício da empresa do período entre 2003 e 2009, que são enviados anualmente para a Comissão de Valores Mobiliários (CVM), o custo médio com paradas não programadas subiu de U\$ $\$ 93,2$ milhões nos últimos seis anos para U\$\$ 418 milhões no ano de 2009, o que representa um aumento de $448 \%$. (PETROBRAS, 2010) A empresa integra o índice Down Jones de Sustentabilidade Empresarial (DJSI), fortalecendo suas ações no mercado internacional. (DJSI, 2010) Segundo o balanço social da organização, as metas anuais para minimização de resíduos visando o consumo, em geral, na produção/operação e o aumento na eficácia da reutilização de recursos naturais, estão sendo realizadas em uma faixa de 75 a $100 \%$. No entanto, os resultados divulgados pela empresa revelam que, ao final de 2008 , foram investidos apenas $0,89 \%$ do rendimento líquido da empresa na área ambiental e 0,05\% em saúde e segurança. (PETROBRAS, 2008 apud IBASE, 2010) Esses dados apoiam a hipótese de que a empresa tem atuado dentro de uma óptica reativa, causando desgastes desnecessários à sua imagem, a exemplo da recente saída do índice Bovespa de Responsabilidade Social por não atingir metas ambientais no Brasil. (BOVESPA, 2010) Segundo a RepRisk (s.d.), empresa responsável pela análise dos riscos de operação das empresas do setor de Petróleo, a empresa utilizada como caso de estudo desta pesquisa está posicionada entre as 10 empresas do setor com grau mais elevado de risco de operação.

O local de armazenamento temporário do resíduo de catalisador removido por varrição possui isolamento, com sinalização de segurança que identificava áreas definidas da instalação e os riscos de acesso ao local, dificultando o acesso de pessoas estranhas, conforme determina norma técnica da Associação Brasileira de Normas Técnicas (1992). No entanto, esse local é uma Área de Proteção Ambiental (APA), para 
a qual a legislação prevê fiscalizações, disciplina sobre o uso e ocupação do solo, entre outros condicionantes. (BAHIA, 1999) Esta APA é uma área sensível, por estar próxima a um mangue e 'habitat' de espécies protegidas. Entretanto, no passado, já recebeu recarga de aquíferos de forma direta, pelas chuvas, e, indireta, alimentada por uma bomba instalada sobre uma lagoa adjacente ao local. A Figura 2 mostra o local de armazenamento temporário do catalisador removido da área industrial por varrição, feita por trabalhadores terceirizados, no ano de 2007. O processo de terceirização neste caso, além de expor desnecessariamente o trabalhador, transfere a responsabilidade da empresa às contratadas para com a destinação final do resíduo de catalisador de craqueamento. Entretanto, o Decreto $n^{\circ} 7.967$ delega esta responsabilidade ao gerador do resíduo. (BAHIA, 2001a)

Figura 2 - Catalisador usado removido por varrição da área industrial e armazenado em local temporário da refinaria.

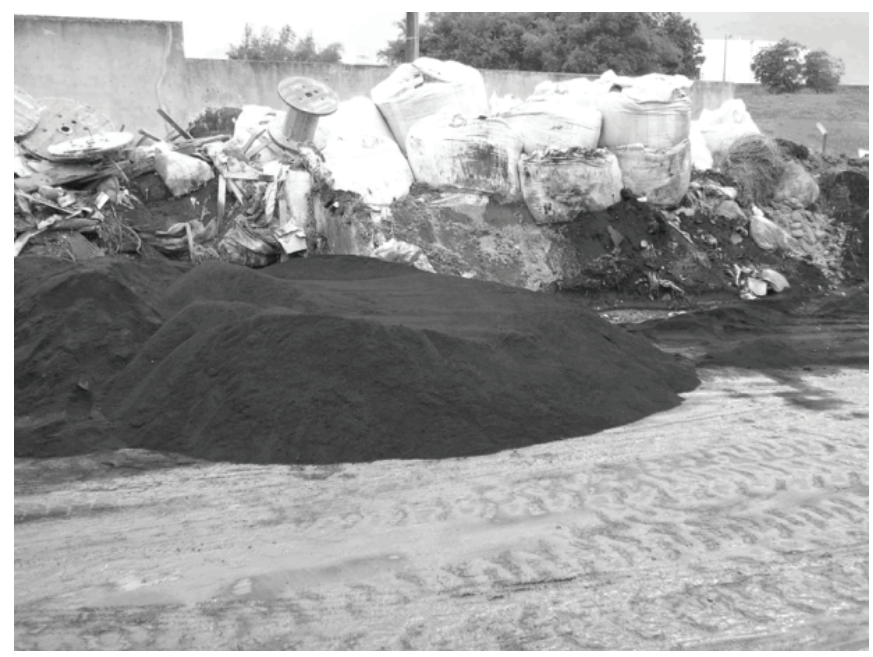

Fonte: PETROBRAS, 2007, apud BAHIA, 2007, p. 57 e 58.

Grande parte do arcabouço jurídico voltado para as questões ambientais e sociais é fruto da mobilização da sociedade civil, iniciada ao final da década de 80, visando sair da óptica corretiva para a preventiva, quando o conceito de Responsabilidade Social começou a se formar no Brasil. A competição pela liderança, visando à geração mínima de resíduo como prioridade de gestão, aumenta os ganhos de sustentabilidade dos negócios. Resultados positivos na marca da organização refletem 
diretamente na imagem da empresa, consequentemente elevando o lucro nos seus investimentos.

Deve ser ressaltada a falta de cooperação dos técnicos da empresa e dos órgãos estaduais de meio ambiente da Bahia e de Sergipe, responsáveis pela fiscalização, que dificultaram a determinação da quantidade e o destino do resíduo de catalisador removido por varrição da área industrial da refinaria.

Como resultado da divulgação da presente pesquisa, a empresa introduziu no processo produtivo uma nova metodologia para injeção de antimônio, reduzindo o contato dos trabalhadores com este metal pesado e minimizando a toxicidade desse resíduo. Em vista dessa prática, torna-se recomendável a revisão da gestão ambiental para este resíduo tóxico de forma multidisciplinar, com a participação dos demais atores sociais envolvidos: órgãos de controle ambiental; poder público; populações sob influência e instituições de pesquisas. Recomenda-se também o cumprimento imediato dos requerimentos legais e normativos cabíveis.

\section{Considerações finais}

As unidades de craqueamento catalítico das refinarias se constituem em fontes relevantes de material particulado e, sobretudo, pelo risco que representa a composição dos finos de particulados contendo metais tóxicos para a saúde e o ambiente em geral. Os resultados da pesquisa indicam que existe um potencial de descarte e perda para o meio ambiente de cerca de 11 toneladas diárias de finos de catalisador exausto, sendo que somente em torno de 5 toneladas possui alguma medida sistemática adotada. As perdas para a atmosfera, que compreendem mais da metade da carga total, não está devidamente gerenciadas e suas consequências nas comunidades vizinhas e no ambiente de trabalho, são desconhecidas ou sem a devida divulgação pela empresa e pelas autoridades ambientais.

Essas constatações sugerem que as medidas de gerenciamento ambiental adotadas na refinaria analisada estão insuficientes para equacionar e minimizar os riscos ambientais que ocasionam e, portanto, aquém das expectativas de uma empresa que se diz publicamente comprometida com a responsabilidade socioambiental. 


\section{Referências}

ASSOCIAÇÃO BRASILEIRA DE NORMAS TÉCNICAS.

NBR 12235: armazenamento de resíduos sólidos perigosos.

Rio de Janeiro, 1992. Disponível em: <http://www.abnt. org.br/default.asp> Acesso em: 26 mar. 2011.

. NBR 10004: resíduos sólidos - classificação. Rio

de Janeiro, 2004. Disponível em: < http://www.abnt.org. br/default.asp > Acesso em: 26 de mar. 2011.

ACGIH - American Conference of Industrial Hygienists. Cincinnati, Ohio 45240. USA: 2010. Disponível em: < http://www.acgih. org/about/history.htm> Acesso em: 21 mar. 2010.

AFONSO, J. C.; AGUIAR, R. M.; SILVA, G. C. O problema do descarte de catalisadores industriais de hidrotratamento. Boletim técnico.

Petrobras, Rio de Janeiro, v. 46, n. 3/4, p. 325 - 333, jul. /dez. , 2003.

Disponível em: <http://pessoal. utfpr. edu. br/ marlenesoares/ arquivos/recuper_niquel2. pdf > Acesso em: 26 mar. 2011.

ALMEIDA, E. S. Caracterização parcial do material particulado atmosférico na região de Paulínia usando o modelo de receptores. 2000. 76f. Dissertação (Mestrado em Química) Instituto de Química, Universidade de Campinas, 2000. Disponível em: < http://biq. iqm. unicamp. br/arquivos/teses/vtls000219849. pdf> Acesso em: 20 mar. 2010.

BAHIA. Secretaria do Meio Ambiente. Resolução CEPRAM n. 13. Aprova a modificação da Resolução $\mathrm{n}^{\circ} 313$, de 30.05 .84 e seus anexos, que dispõe sobre o controle de resíduos sólidos perigosos no estado da Bahia. Diário Oficial do Estado da Bahia, 1, 2 ago. 1987, Bahia. Brasil: 1987. Disponível em: < http://www.meioambiente.ba.gov.br/legislacao/resolucao_ cepram/Resolucao_13_29_julho_1987.pdf> Acesso em: 26 mar. 2011.

. Secretaria do Meio Ambiente. Resolução CEPRAM n. 1. 039. Aprova a Norma Administrativa NA001/94, que dispõe sobre o Controle do Transporte Rodoviário de Produtos e Resíduos Perigosos no Estado da Bahia. Diário Oficial do Estado da Bahia, 31 mar. 1995, Bahia. Disponível em: < http://www.sema.ba.gov.br/legislacao/resolucao_cepram/ Resolucao_1039_06_dezembro_1994.pdf> Acesso em: 26 mar. 2011.

. DECRETO no 7. 595 de 05 de junho de 1999. Cria a área de proteção ambiental - APA da Baía de Todos os Santos e dá outras providências. Diário Oficial do Estado da Bahia, 09 jun. 1999, Bahia. Brasil: 1999. Disponível em: <http://www.semarh.ba.gov.br/ DecretosUnidadesdeConservacao/Dec7595.pdf> Acesso em: 26 mar. 2011. 
BAHIA. DECRETO n ${ }^{\circ} 7.967$ de 05 de junho de 2001. Aprova o Regulamento da lei $n^{\circ} 7.799$, de 07 de fevereiro e 2001, que institui a política estadual de administração de recursos ambientais e dá outras providências. Publicado no Diário Oficial do Estado, Bahia, 06 jun. 2001a. Disponível em: <http:// www.semarh.ba.gov.br/Legislacao/Decretos\%20Estaduais/Meio\%20 Ambiente-Biodiversidade/Dec7967.pdf> Acesso em: 26 mar. 2011.

. CRA. Centro de Recursos Ambientais. PORTARIA CRA n ${ }^{\circ}$ 1. 225. Aprova a renovação da licença de operação da RLAM. Salvador. Bahia. Brasil: 2001b. Impresso.

. CRA. Centro de Recursos Ambientais. Termo de referência com instruções para elaboração do plano de gerenciamento de resíduos sólidos - PGRS. Bahia. Brasil, 2002. Disponível em: < http://www.derba. ba.gov.br/download/meioambiente/4.pdf> Acesso em: 26 mar. 2011.

. CRA. PORTARIA CRA n ${ }^{\circ} 6.672$. Aprova a renovação da licença operação da RLAM. Salvador. Bahia. Brasil, 2006. Impresso.

. Ministério Público Estadual. Inquérito civil público 003. 1. 13889/2007 pelo Ministério Público Estadual - Primeira Promotoria de Justiça do Meio Ambiente de Salvador, para averiguar denúncia de degradação ambiental consistente no lançamento de metais pesados causando contaminação de moluscos e adoecimento de trabalhadores pela RLAM/PETROBRAS. Salvador - Bahia. 2007.

BAPTISTA, A. Avaliação do potencial de recuperação de metais de catalisadores equilibrados através da técnica de remediação eletrocinética. 2005. 152f. Dissertação (Mestrado em Engenharia de Materiais e Processos) Universidade Federal do Paraná. Curitiba, 2005. Disponível em: < http://dspace. c3sl. ufpr. br/dspace / bitstream/1884/2583 /1/DISSERTACAO\%20VERSAO\%20FINAL\%20 ADALBERTO \%20BAPTISTA. pdf . >Acesso em: 26 mar. 2011.

BIRA, M. Os desafios tecnológicos do refino de petróleo no Brasil - perspectivas futuras. UNIFEI, ago. 2004. Disponível em: <http://www.prh16.unifei.edu.br/downloads/palestra petrobras2004.ppt> Acesso em: 09 mar. 2010.

BOVESPA. Bolsa de Valores do Estado de São Paulo. Disponível em: <http://www.bmfbovespa.com.br/indices/ResumoIndice. aspx ? Indice =ISE\&Idioma=pt-BR $>$ Acesso em: 09 mar. 2010.

BRASIL. Ministério do Trabalho e Emprego. Norma Regulamentadora n $^{\circ} 15$ - Atividades e Operações Insalubres, Portaria no 3. 214, de 8 jun. 1978. . Resolução CONAMA nº 001, de 23 de janeiro de 1986. Estabelece as definições, as responsabilidades, os critérios básicos e as diretrizes gerais 
para uso e implementação da avaliação de impacto ambiental como um dos instrumentos da política nacional do meio ambiente. Publicação - Diário Oficial da União, Brasília, 17 fev. 1986. Disponível em: < http://www.mma. gov.br/port/conama/res/res86/res0186.html > Acesso em: 26 mar. 2011.

BRASIL. Lei Federal n ${ }^{\circ}$ 7. 735. Dispõe sobre a extinção de órgão e de entidade autárquica, cria o Instituto Brasileiro do Meio Ambiente e dos Recursos Naturais Renováveis (IBAMA) e dá outras providências. Publicado no Diário Oficial da União, Brasília, 23 fev. 1989. Disponível em: < http://www. planalto.gov.br/ccivil_03/Leis/L7735.htm> Acesso em: 26 mar. de 2011.

. Lei no 9. 099. Dispõe sobre os juizados especiais cíveis e criminais e dá outras providências. Publicada no Diário Oficial da União, 26 set. 1995. Brasil: 1995. Disponível em: <http://www. planalto.gov.br/ccivil_03/Leis/L9099.htm> Acesso em: 26 mar. 2011.

. Resolução no 196 Conselho Nacional de Saúde - CNS. Aprova as diretrizes e normas regulamentadoras de pesquisas envolvendo seres humanos. Diário Oficial da União, Brasília, n. 201, 16 out. 1996. Disponível em: <http://www.ufrgs.br/ bioetica/res19696.htm > Acesso em: 26 mar. 2011.

. Lei Federal no 9. 605. Dispõe sobre as sanções penais e administrativas derivadas de condutas e atividades lesivas ao meio ambiente, e dá outras providências. Diário Oficial da União. 13 fev. 1998. Disponível em: <http://www. planalto. gov. br/ ccivil_03/Leis/L9605. htm> Acesso em: 26 mar. 2011.

. Presidência da República. Casa Civil. Subchefia para Assuntos Jurídicos Lei $\mathrm{N}^{\circ} 10.650$, de 16 de abril de 2003. Dispõe sobre o acesso público aos dados e informações existentes nos órgãos e entidades integrantes do SISNAMA. Diário Oficial da União, 17 abr. 2003. Disponível em: < http://www. planalto. gov. br/ ccivil_03 /Leis/2003/L10. 650. htm> Acesso em: 26 mar. 2011.

BRASIL. Resolução CONAMA n 382 , de 26 de dezembro de 2006. Estabelece os limites máximos de emissão de poluentes atmosféricos para fontes fixas. Diário Oficial da União. n. 1, 02 jan. 2007. Disponível em: <http://www. mma. gov. br/port/ conama/ res/res06/res38206. pdf> Acesso em: 26 mar. 2011.

CASTRO, H. A.; GOUVEIA, N.; ESCAMILIA-CEJUDO, J. A. Questões metodológicas para a investigação dos efeitos da poluição do ar na saúde. Revista Brasileira de Epidemiologia. v. 6, n. 2, 2003. Disponível em: <http://www. scielosp. org/ pdf/rbepid/v6n2/07. pdf> Acesso em: 26 mar. 2011. 
CB\&I - CHICAGO BRIDGE \& IRON COMPANY. Fluid Catalytic Cracking. Hague. Netherlands 2009. Disponível em: < http://www. cbi. com/ images/uploads/tech_sheets/FCC. pdf $>$ Acesso em: 26 mar. 2011.

CCOHS. Canadian Centre for Occupational Health \& Safety. Canadá, 2009. Disponível em: <http://www. ccohs. ca/oshanswers/ chemicals/convert. html> Acesso em: 09 mar. 2010.

CERQUEIRA, H. S. et al. Avaliação da efetividade do antimônio para passivação de níquel nas refinarias da PETROBRAS. Boletim Técnico PETROBRAS, Rio de Janeiro, v. 44, n. 1/4, p. 29-36, jan. /dez. 2001.

; BAPTISTA, C. M. L. A.; FUSCO, J. M. O que acontece no vaso "stripper" de uma UFCC? FCC em Revista. n. 47, Ano VIII, abr. /maio/ jun. 2006. Disponível em: < http://www. fccsa. com. br/templates/ fccsa2010/Publicacao/ Revistas. asp?cod_Canal $=25 \&$ cod_pai $=360 \&$ cod_ grupo $=0 \&$ cod_publicacao $=349 \&$ cod_idioma $=0>$ Acesso em: 08 mar. 2010.

; RAWET, R.; PINTO, J. C. La Influencia de los Errores

Experimentales Durante La Evaluación Laboratorial de Catalizadores de FCC . FCC en Revista, v. 23, n. 3 p. 15. , 2000

CORRADI, S. R. Ecoeficiência na indústria de petróleo: o estudo do craqueamento catalítico na PETROBRAS. 2008. Dissertação (Mestrado em Gestão Empresarial) Escola Brasileira de Administração Pública e Empresas - Fundação Getúlio Vargas, 2008. Disponível em: <http://virtualbib. fgv. br/dspace/bitstream/ handle/10438/3758/ scorradi. pdf? sequence =1> Acesso em: 26 mar. 2011.

COSTA, A. F. et. al. Preparo de catalisadores de FCC modificados com siloxanos para redução do índice de atrito e aumento da acessibilidade. Boletim Técnico Petrobras, Rio de Janeiro, v. 47, n. 2/4, p. 255 - 265, abr. /dez. 2004.

DEJOURS, C. Introduction: psychodynamique du travail. Revue Internationale de Psychosociologie, n. 5, p. 5-12, 1996.

DRUCK, G.; FRANCO, T. (orgs. ). A perda da razão social do trabalho: terceirização e precarização. São Paulo: Boitempo, 2007.

DJSI. Dow Jones. Sustainability Indexes. Zurich. Switzerland, 2010. Disponível em: < http://www. sustainabilityindex. com/> Acesso em: 09 mar. 2010.

ENVIRONMENTAL PROTECTION AGENCY. Hazardous Waste Minimization and Management Division Office of Solid Wastw. Waste Minimization for Selected Residuals in the Petroleum 
Refining Industry. Washington. D. C. 1996. Disponível em: < http:// www.epa.gov/nscep/index.html> Acesso em: 26 mar. 2011.

FCC S. A. Fábrica Carioca de Catalisadores. Aumento na produção de catalisadores no País. Rio de Janeiro, 2005. Disponível em: $<$ http://www. fccsa.com.br/templates/fccsa/noticia/noticia.asp?cod_ canal $=1 \&$ cod_noticia=6\&cod_idioma=0 $>$ Acesso em: 09 mar 2010.

FCC S. A. Fábrica Carioca de Catalisadores. Ficha de Informação de Segurança de Catalisador. Rio de Janeiro, 2010. Impresso

FIEB. Federação das Indústrias do Estado da Bahia - Cadastro do guia industrial do estado da Bahia. Brasil: 2010. Disponível em: < http://www. fieb. org. br/guia/dados_industria. asp? industria $=1778>$ Acesso em: 26 mar. 2011.

GODINHO, L. F. R. Laços frágeis, labor trincado: Interação, discriminações e conflitos entre trabalhadores da Refinaria Landulpho Alves - 1990-2005. Revista Estudos do Trabalho, Marilia, UNESP, Ano I, n. 1, 2007. Disponível em: < http://www. estudosdotrabalho. org > Acesso em: 27 mar. 2011.

IBASE. Instituto Brasileiro de Análises Sociais e Econômicas.

Relativo aos balanços sociais do modelo IBASE publicados no portal Balanço Social. 2010. Disponível em: <http:// www. balancosocial. org.br/> Acesso em: 09 mar. 2010.

IBGE. Instituto Brasileiro de Análises Sociais e Econômicas. Produto interno bruto dos municípios 2002 - 2005, Rio de Janeiro, 2007. Disponível em < http://www. ibge. gov. br>/ Acesso em: 21 mar. 2007

MARIANO, J. B. Impactos ambientais do refino de petróleo. COPPE/UFRJ, M. Sc. , Planejamento Energético. Rio de Janeiro, 2001. Disponível em: <http://www. ppe. ufrj. br/ppe/ production/tesis/jbmariano. pdf > Acesso em: 26 mar. 2011.

NATIVOS da Ilha de Maré adoecem devido à poluição por produtos tóxicos.

A Tarde on line. Salvador - BA, 2010. Disponível em: <http://www. atarde. com. br/cidades/noticia. jsf?id=1413796> Acesso em: 9 mar. 2010.

NEVES, N. M. S.; MENEZES, P. S. F.; ASSUNÇÃO, R. S. Rede de monitoramento do ar na área de influência da Refinaria Landulpho Alves - RLAM. Congresso Brasileiro de Engenharia Sanitária e Ambiental, 21ㅇ, 2001. Disponível em < http://www. bvsde. paho. org/bvsaidis/brasil21/vi-110. pdf> Acesso em: 27 mar. 2011

NIOSH - The National Institute for Occupational Safety and Health. GA 30333, Atlanta, USA. 2010. 
PETROBRAS/ABAST/PG-1T-00020-A. Cópia não controlada do padrão de responsabilidade social no abastecimento da PETROBRAS - Brasil, 2006.

PETROBRAS. Informações obtidas do portal eletrônico da PETROBRAS, s. d. . Disponível em: <www. petrobras. com. br> Acesso em: 21 mar. 2010.

PPGSAT. Programa de Pós-graduação em Saúde, Ambiente e Trabalho pela Faculdade de Medicina da UFBA. Mestrandos produzem vídeo sobre poluição atmosférica em São Francisco do Conde. 15 ago. 2010. Disponível em: < http://www. sat. ufba. br/site/ main. asp?view $=$ noticia\&id $=388>$ Acesso em: 2 mar. 2011

REPRISK. Reputational Risk Radar. Zurich, Switzerland. Disponível em: $<$ http://www. reprisk. com/downloads/innews/100917\%20Petrobras\%20 esta\%20entre\%20empresas\%20mais\%20controversas\%20do\%20setor\%20 diz\%20consultoria\%20europeia. pdf> Acesso em: 19 out. 2010.

RIBEIRO, F. C.; FLORES, M. G. Fluidização - conceitos e troubleshooting. FCC en Revista, ANO XV , n. 53,. Brasil: 2008.

SAI, Social Accountability International. Norma de responsabilidade social SA-8000. - [2008] Disponível em: <http://www. sa-intl. org/_ data/n_0001/resources/live/ 2008StdEnglish Final. pdf >EUA: 2008.

SALGADO, P. E. T. Informações gerais e ecotoxicológicas de material particulado. Salvador: Centro de Recursos Ambientais CRA, 2003. 156 p. (Cadernos de Referência Ambiental, v. 14).

SANTOS, E. L. Estudo sobre a utilização de resíduos industriais não-inertes e perigosos na produção de cimento. São Paulo, 2005. Disponível em: <http://www. ecelambiental. com. br/artigos/UTILIZACAO_RESIDUOS_PERIGOSOS FORMULACAO_CIMENTO. pdf> Acesso em: 09 mar. 2010.

SBRT. Serviço Brasileiro de Respostas Técnicas. Ciclones e lavadores de gases. - Disponível em < http:// www. sbrt. ibict. br> Acesso em: 12 mar. 2007.

SILVA, B. B. et al. Potencial eólico na direção predominante do vento no nordeste brasileiro. Revista Brasileira Engenheira Agrícola Ambiental [online]. v. 6, n. 3, p. 431-439. 2002. Disponível em: <http://www. scielo. br/pdf/rbeaa/v6n3/v6n3a09. pdf> Acesso em: 13 mar. 2012. SILVA JÚNIOR, W. F; AGRA FILHO; CARVALHO. Avaliação da poluição atmosférica por HPAS em material particulado - MP10, no Distrito de CAÍPE, Município de São Francisco do Conde - Bahia. Apresentado em formato pôster e publicado em edição suplementar 
da Revista Ciência e Saúde Coletiva (ISSN1413-8123) - Anais do IX Congresso Brasileiro de Saúde Coletiva. Recife - Brasil: 2009.

SILVA JÚNIOR, W. F. Avaliação da gestão ambiental de uma Refinaria de Petróleo para as perdas de catalisador de craqueamento.

2010. 106f. Dissertação (Mestrado em Saúde, Ambiente e Trabalho)

Faculdade de Medicina da Bahia, Universidade Federal da Bahia, 2010. Disponível em: < http://www. sat. ufba. br/site/db / dissertacoes/1272010185144. pdf> Acesso em: 03 out. 2010.

TORRES, F. T. P.; MARTINS, L. A. Fatores que influenciam na concentração do material particulado inalável na cidade de Juiz de Fora (MG). Caminhos de Geografia, v. 4, n. 16, p. 23-39, out. 2005. Disponível em <http:// www. ig. ufu. br/revista/caminhos. html> Acesso em: 05 out. 2011.

VAZQUEZ, P. S. Análise da presença de violência/assédio moral na organização e gestão do trabalho na PETROBRAS. 2009.

Disponível em <www. aepetro. org. br> Acesso em: 15 mar. 2011.

WMA - World Medical Association. International Code of

Medical Ethics. Disponível em: <http://www. wma. net/

en/30publications/10policies/c8/index. html> Acesso 03 out. 2010.

WIKIMEDIA FOUNDATION, Inc. Fluid Catalytic Cracking.

2011. Disponível em: < http://en. wikipedia. org/wiki/

Fluid_catalytic_cracking > Acesso em: 26 mar. 2011. 